\title{
Protective and genotoxic effect of food coloring.
}

\author{
Mostafa Norizadeh Tazehkand*
}

Department of Pharmaceutical Biotechnology, Faculty of Pharmacy, Bulent Ecevit University, Zonguldak, Turkey

\begin{abstract}
Food additives adding to food and some drinking to protect taste or improve its flavor and quality, it has been used for centuries to help ease processing, packaging, and storage. Food additives are classified as colors, antimicrobial agents, anti-fungal agents, and flavor enhancers. Antimicrobial agents including salts, sorbic acid, vinegar and calcium propionate are used in the products like salad dressings, margarine, cheese and pickled foods. Antioxidant agents such as vitamin C, vitamin E, BHT and BHA are using in the foods containing high fats. Food additives are significant in drinking and food manufacturing firms.
\end{abstract}

Keywords: Genotype, Biotechnology, pharmaceuticals, Vitamin, Blood.

Accepted on 28 March, 2018

\section{Commentary}

Food coloring is one of food additive agents that we used in food and some drinking. Food coloring or food dye, is any color, pigment or material that give color to food or drinks. There are many types of food coloring including liquids, powders and gels. Food dyes is used both in commercial food production and in domestic cooking. Also, Food dyes are using in non-food applications such as cosmetics, pharmaceuticals and medical devices [1,2]. The addition of any dye to foods is thought to have comprised in Egypt as early as 1500 Before Christ, when candy makers added to wine for improve the wine appearance [3].One of first food canons, formed in Germany relevance spices or dyes and required saffron counterfeiters to be burned [4].

Food coloring are natural or synthetic agents. Carotenoids (E160, E161, E164), chlorophyllin (E140, E141), anthocyanins (E163), and betanin (E162) including four basic categories of plant pigments grown to color food products [5]. Other colorants or specialized derivatives of these core groups following as: Annatto, Caramel coloring, Carmine, Elderberry juice, Lycopene, Paprika and Turmeric are natural food color that we use in our foods or drinks. There are many permitted artificial food dyes that people use on their foods. We listed some of usable colors as following as:

EU: Some artificial dyes approved for food use in the EU include: E104 (Quinoline Yellow), E122 (Carmoisine), E124 (Ponceau 4R), E131 (Patent Blue V) and E142 (Green S ) [6].

U.S: Some artificial dyes approved for food use in the EU include: Brilliant Blue FCF, Indigotine, Fast Green FCF, Erythrosine, Allura Red AC, Tartrazine, Sunset Yellow FCF [2].

Two colors are allowed by the FDA for limited applications: Citrus Red 2 that allowed only to color orange peels and Orange $\mathrm{B}$ that allowed only for use in hot dog and sausage casings $[7,8]$.
Some of food coloring have not tested for toxicity or other risk effects. Abe and Sasaki showed that azo dyes induced chromosomal aberrations in Chinese hamster ovary cells [9]. Patterson and Butler aimed to study of genotoxic effect of tatrazine in mammalian cells. The result of this study revealed that Tatrazine induced chromosomal aberrations in lymphocytes of Muntiacus muntjac [10]. In another study Roychoudhury and Giri investigated the effect of indigo carmin, orange $\mathrm{G}$ and tatrazine on human peripheral blood lymphocytes [11]. The results obtained from this study showed that high concentrations of indigo carmin, orange $G$ and tatrazine induced chromosome breaks and micronucleus formation in blood lymphocytes (Giri et al. [11]). Ozaki et al. investigated the genotoxic effect of red 3 , red 40, red 102, blue 1 and blue 2 synthetic colors on Mouse bone marrow cells [12]. The result of this study was showed that blue 2 induced chromosomal aberrations [12]. Agarwala et al. reported that safflower yellow and kokum red weakly increased chromosomal aberrations in bone marrow cells of Swiss albino male mouse Agarwala et al. [13] Same result obtained from Tazehkand, et al. the researchers studied the genotoxic effect of 4-methylimidazole on bone marrow cells of albino mice [14]. The result of this study was showed that the 4-methyl imidazole do not induce chromosome aberrations on albino mice.

Some food colors don't have genotoxic effect, for example, Brusick et al. reported that sulfite-ammonium caramel did not induce chromosomal aberrations in Chinese hamster ovary cells [15]. Santos et al. reported that Bixa orellana L. extract including annatto dye did not induce micronucleus [16]. The researchers showed that the annatto dye do not genotoxic effect on cells. In contrast to food dyes that have genotoxic effect on humans and mouse, there are some food colors that have protective effect against carcinogenic agents. In another study Mukherjee et al. investigated the anti genotoxic effect of beta karoten (natural dye) against cyclophosphamide in bone marrow cells of rats by micronucleus assay [17]. The result of this study revealed that beta karoten reduced the genotoxic effect of cyclophosphamide. Tazehkand, et al. investigated the 
in vivo antigenotoxic effect of 4-methyl imidazole against ethyl methane sulfonate [18]. The result obtained from this study revealed that 4-methyl imidazole does not antigenotoxic and protective effects in bone marrow cells of Abino Mice [14]. Same researcher's testes the 4-methyl imidazole effect on different cell lines. The result of these studies showed that 4MEI has cytotoxic effect on 3T3-L1 and colon cancer cell lines and induce necrosis on rat liver cells $[14,18,19]$. Izawa et al. [20] reported that red and yellow pigments from Monascus has inhibitory effect against the bacterial mutagenicity of heterocyclic amines [20]. Edenharder and Tang, who observed the antimutagenic effect of purpurin, alizarin and other 10 anthraquinone compounds using the Ames test [21]. Similar results were obtained by Rayes who found the Cola soft drink had toxic effect on the mice testicular cells [22-24]. According to our and other researcher's results, some of food dyes usually induce genotoxicity. Therefore, some of food coloring do not induce genotoxicity but some of them have protective effects.

\section{References}

1. Pandey RM, Upadhyay SK. Food Additive. Division of Genetics, Plant breeding \& Agrotechnology, National Botanical Research Institute, Lucknow, India 2012.

2. FDA. CFR Title 21 Part 70: Color Additive Regulations. 2012.

3. Meggos H. Food colours: an international perspective. The Manufacturing Confectioner. 1995;59-65.

4. Jim C. Colorants Compliance. The World of Food Ingredients. Arnhem, The Netherlands: CNS Media BV. 2013;41:3.

5. Rodriguez-Amaya DB. Natural food pigments and colorants. Curr Opin Food Sci. 2016;7:20-6.

6. Freeman IP, "Margarines and Shortenings" Ullmann's Encyclopedia of Industrial Chemistry, 2005.

7. FDA. Red No. 3 and Other Colorful Controversies". FDA. Archived from the original on 2007.

8. New York Times. The use of artificial colors to make foods more attractive to the eye may be sharply curtailed by action of the United States Food and Drug Administration. Three of the most extensively used food colorants are being considered for removal from the Government's list of colors certified as safe for internal and external use and consumption. 1954.

9. Abe S, Sasaki M. Chromosome Aberrations and Sister Chromatid Exchanges in Chinese Hamster Cells Exposed to Various Chemicals. Oxford Journals Medicine. 1976;58(6): 1635-41.

10. Patterson RM, Butler JS. Tartrazine-induced chromosomal aberrations in mammalian cells. Food Chem Toxicol. 1982;20(4):461-5.

11. Giri AK, Sivam SS, Khan KA, et al. Sister chromatid exchange and chromosome aberrations in mice after in vivo exposure of green S-A food colorant. Environ Mol Mutagen. 2006;19(3):223-6.

12. Ozaki A, Kitano M, Itoh N, et al. Mutagenicity and DNAdamaging Activity of Decomposed Products of Food
Colours under UV irradiation. Food Chem Toxicol. 1998;36(9):811-7.

13. Agarwala K, Mukherjee A, Chakrabarti. In vivo cytogenetic studies on mice exposed to natural food colourings. Food Chem Toxicol. 1994;32(9):837-83.

14. Tazehkand MN, Topaktas M, Yilmaz MB, et al. Delineating the antigenotoxic and anticytotoxic potentials of 4methylimidazole against ethyl methanesulfonate toxicity in bone marrow cell of swiss albino mice. Bratisl Lek Listy 2016;117(5):290-4.

15. Brusick DJ, Jaqannath DR, Galloway SM, et al. Genotoxicity hazard assessment of caremel colours III and IV. Food Chem Toxicol. 1992;30(5):403-10.

16. Santos CDG, Mendonça LM, Antonucci GA, et al. Protective effect of bixin on cisplatin-induced genotoxicity in PC12 cells. Food Chem Toxicol. 2012;50(2):335-40.

17. Mukherjee A, Agarwala K, Aguilar MA et al. Anticlastogenic activity $\beta$-carotene against cyclophoshamide in mice in vivo. Mutat Res. 1991;263(1): 41-6.

18. Tazehkand MN, Topaktas M, Yilmaz MB. Assessment of Chromosomal Aberration in the Bone Marrow Cells of Swiss Albino Mice Treated by 4-Methylimidazole. Drug Chem Tox. 2015;39:3, 307-11.

19. Tazehkand MN. Antiproliferative effect of a food coloring on colon cancer cell line. Bratisl Lek Listy. 2017;118(5): 265-8.

20. Izawa S, Harada N, Watanabe T, et al. Inhibitory effects of food-coloring agents derived from Monascus on the mutagenicity of heterocyclic amines. J Agric Food Chem 1997;45:3980-4.

21. Edenharder R, Tang X. Inhibition of the mutagenicity of 2nitrofluorene, 3-nitrofluoranthene and 1-nitropyrene by flavonoids, coumarins, quinones and other phenolic compounds. Food Chem Toxicol. 1997;(35):357-72.

22. Rayes AAH. Effect of Some Drinks on the Benificial Probiotic Bacteria and the Structure of Testis of Male Albino Mice. J Appl Sci Res. 2008;4(7):803-13.

23. Tazehkand MN, Hajipour O, Moridikia F, et al. Investigation of anticarcinogenic and antioxidant effects of -methylimidazole. Bratisl Lek Listy. 2017;118(3):149-52.

24. Tazehkand MN, Moridikia A, Hajipour O, et al. The effects of 4-MEI on cell proliferation, DNA breaking and DNA fragmentation. Bratisl Lek Listy 2016;117(7):371-5.

\section{*Correspondence:}

Mostafa Norizadeh Tazehkand

Department of Pharmaceutical Biotechnology,

Bulent Ecevit University,

Turkey

E-mail: mostafa.norizadeh@beun.edu.tr

Tel +903722911100 